Redes, bibliotecas e literacias

Atas do $I^{\circ}$ Seminário da Rede de Bibliotecas de Évora

Publicações do Cidehus

\title{
As bibliotecas na era da informação
}

os desafios das tecnologias da informação

\section{Francisco António Lourenço Vaz}

DOI: 10.4000/books.cidehus.2599

Editora: Publicações do Cidehus

Lugar de edição: Évora

Ano de edição: 2017

Online desde: 16 Março 2017

coleção: Biblioteca - Estudos \& Colóquios

ISBN eletrónico: Biblioteca - Estudos \&

Colóquios

\section{Sbooks}

http://books.openedition.org

\section{Refêrencia eletrónica}

VAZ, Francisco António Lourenço. As bibliotecas na era da informação: Os desafios das tecnologias da informação In: Redes, bibliotecas e literacias: Atas do 10 Seminário da Rede de Bibliotecas de Évora [online]. Évora: Publicações do Cidehus, 2017 (generated 27 March 2017). Available on the Internet: <http:// books.openedition.org/cidehus/2599>. ISBN: 9782821879546. DOI: 10.4000/books.cidehus. 2599. 
As bibliotecas na era da informação - Os desafios das tecnologias da informação Francisco António Lourenço Vaz

\section{Resumo}

Nesta comunicação procuramos compreender o impacto da revolução das tecnologias da informação nas bibliotecas públicas, nomeadamente, no que se refere às alterações provocadas na cultura impressa com o aparecimento do texto eletrónico. Numa primeira parte, fazemos a contextualização sobre as grandes mudanças operadas com a revolução do TIC, partindo do pressuposto que entramos numa Era da Informação. Situamos a nossa análise num tempo longo de modo a encarar esta revolução de finais do século XX, como mais uma, entre várias revoluções da informação, de que são bons exemplos: a invenção da escrita, o aparecimento do códex e a revolução da imprensa de Gutenberg, em meados do século XV. Numa segunda, caracterizamos as mudanças operadas nas bibliotecas públicas pela introdução das tecnologias da informação, tomando como base duas atitudes que a História do Livro e da Leitura documenta, pelo menos desde a invenção da imprensa, o medo da perda do património bibliográfico, ou salvaguarda da memória de todos os textos e livros produzidos, e o de excesso de informação, ou de textos e livros que são cada vez mais e, como tal, nenhum erudito pode aspirar a ler toda essa imensa massa documental. É nesta dialética, entre a perda e excesso, que consideramos que o papel das bibliotecas na era da informação deve ser de continuidade, em muitas das ideias e dos fins para que foram criadas ao longo dos tempos, e de responder aos novos desafios que a o presente lhe coloca.

Palavras-chave: era da informação, TIC, biblioteca pública, memória, literacia

\section{A era da informação e a revolução das TIC}

É vulgar dizer-se que estamos na sociedade da informação, que a informação é o petróleo do seculo XXI, que os meios de produção foram substituídos pelos meios de informação, que todos os caminhos vão dar a Silicon Valley. Contudo, como bem refere Robert Darnton (2002), esta designação encerra um equívoco porque na realidade todas as sociedades podem ser vistas como sociedades da informação, todas tiveram sistemas de comunicação e informação, todas as sociedades desenvolveram os seus próprios meios de 
colher e reunir informação, usando ou não os conceitos de notícias e "media". Na realidade o que mudou foram os meios de informação. E para esta mudança contribuiu a tecnologia que os homens foram criando e aplicando, para produzir, difundir a informação ${ }^{1}$.

O que as tecnologias têm permitido é a superação de dois obstáculos, que desde a origem se colocaram aos homens, na informação e na comunicação: o tempo e o espaço. Neste domínio as tendências têm sido de os meios de comunicação estenderem ou prolongarem a comunicação no espaço e no tempo. Se, por exemplo, o alfabeto significou a possibilidade de estender a comunicação no espaço, quando comparado com os tradicionais meios, as pinturas das cavernas ou os hieroglíficos do Egito, porque era mais fácil de transportar os suportes da escrita, a imprensa pode ser considerada "o primeiro meio da história a expandir-se mais ou menos uniforme e poderosamente no espaço e no tempo" (Levinson, 1998,77). Esta extensão da informação e da comunicação constitui a grande conquista das tecnologias de informação e comunicação. É sabido que atualmente a informação flui à velocidade da luz, que podemos comunicar em tempo real com qualquer parte do planeta e que podemos enviar e receber, também à velocidade da luz, informação de todo o tipo, incluindo livros, imagens e músicas.

Para compreender o alcance e significado desta revolução das TIC, se nos colocarmos numa perspetiva de longa duração, esta é mais uma de muitas revoluções ao longo da história, tal como foram a invenção da escrita, o alfabeto, o códex, a imprensa, a livraria de massas no seculo XIX e os media ligados à comunicação. Em todas, como refere Paul Levinson $(1998,77)$, a tendência tem sido de superar os obstáculos referidos do tempo e do espaço, em todas outra tendência tem sido de tornar os meios mais humanos no seu desempenho, ou seja, a comunicação através dos meios é cada vez mais igual à maneira natural como os homens processam a informação.

Para a história das bibliotecas importa referir algumas das grandes mudanças que as revoluções anteriores trouxeram. Os livros com que estamos familiarizados, constituídos por folhas dobradas e organizados em cadernos e com uma capa de proteção surgiram muitos séculos depois da invenção da escrita. Esta estrutura de livro foi criada no baixoimpério romano e difundida pelas comunidades cristãs no século IV e V. Foi a revolução do códex e abriu possibilidades até então impensáveis, nomeadamente a possibilidade de

\footnotetext{
1 - Usamos o termo tecnologia no sentido que Manuel Castells lhe atribui, em consonância com Daniel Bell e Harvey Brooks « a utilização de conhecimento científico para especificar as vias de se fazerem coisas de uma forma reprodutível» (Cit. Castells, 2007, 34)
} 
armazenar mais informação em menos espaço e a possibilidade de recuperar a informação com muita mais rapidez, através da paginação e de índices. Para as bibliotecas significou uma nova era em matéria de catalogação, de ordenação e disposição do espaço - os rolos eram preferencialmente arrumados em jarros e não em estantes com prateleiras. A nova estrutura de livro trouxe também uma maior produção de livros e portanto aumentou significativamente as coleções e o número de leitores.

Com a revolução da imprensa no século XV não se alterou a estrutura anterior do livro, mas alterou-se a produção de textos, permitindo a automatização do processo da escrita e consequentemente mais rapidez e uma baixa nos custos dos livros. Entramos como bem referiu Marshal McLuhan na "Galáxia de Gutenberg", numa nova era em termos de acesso ao livro e a leitura. Tal foi o impacto na sociedade que a imprensa é considerada a "parteira da modernidade" ou fator determinante dos movimentos culturais do Humanismo, da Reforma e da Ciência Moderna. Significou, também, o triunfo de uma cultura impressa, tendo como meios os livros, as gazetas e jornais.

A revolução do nosso tempo, a que chamos das Tecnologias da Informação e Comunicação (TIC), situa-se em finais do século XX, embora possamos considerar ter havido uma primeira revolução dos media, desde meados do século XIX, até primeiras década do século XX, com o aparecimento da fotografia, telégrafo, telefone, cinema, da radiodifusão e radiodifusão televisiva; meios que começaram a disputar o quase monopólio da cultura impressa.

A Revolução das TIC insere-se no contexto histórico dos anos setenta do século XX, que ficou marcado por uma conjugação de desafios para os países industrializados que resultaram de três perturbações na ordem mundial pós-1945: em 1971, o fim do regime das taxas de câmbio fixo; em 1973 e 1979 os choques petrolíferos e, em 1971, a revolução californiana do microprocessador e da Engenharia Genética. Para o nosso estudo, interessa fixar a revolução californiana do microprocessador, pois é nesta invenção que estarão muitos dos desenvolvimentos que se vão operar no acesso, organização e recuperação da informação. Esta revolução está centrada mas TIC nas quais se inserem as seguintes tecnologias:

a. O conjunto convergente de tecnologias em microeletrónica e computação software e hardware, tecnologias dos suportes informáticos;

b. As telecomunicações/radiodifusão e optoelectrónica;

c. A engenharia genética por se inserir na descodificação, manipulação, e 
consequente reprogramação dos códigos de informação da matéria viva, mas também porque a biologia, a eletrónica e a informática parecem estar a convergir e a interagir nas suas aplicações e materiais e, de forma mais fundamental, na abordagem conceptual.

Manuel Castells é o autor mais referenciado para descrever as origens e os efeitos na economia e sociedade desta revolução tecnológica que, segundo ele, está centrada nas tecnologias da informação e remodelou "de forma acelerada, a base material da sociedade" (Castells, 2007, 1). Em termos de impacto salienta uma nova forma de economia caracterizada pela eficiência na organização, gestão e uma "substancial taxa de crescimento da produtividade". Outra consequência é a criação de uma "sociedade em rede":

A sociedade em rede, em termos simples, é uma estrutura social baseada em redes operadas por tecnologias de comunicação e informação fundamentadas na microeletrónica e em redes digitais de computadores que geram, processam e distribuem informação a partir de conhecimento acumulado nos nós dessas redes (Castells, 2005, 21).

A sociedade em rede é portanto a consequência mais visível da revolução das TIC e com ela surgiu também um novo conceito de espaço: o ciberespaço, que pela sua virtualidade se revela um espaço com grande impacto a nível económico, dado os baixos custos que possibilitou na produção e difusão da informação. Por outro lado, a sociedade em rede está a reconfigurar não apenas a vida das pessoas, mas também das empresas e organizações, incluindo as bibliotecas e arquivos. Com o ciberespaço, a documentação libertou-se da necessidade de um espaço físico que foi, ao longo dos séculos, um dos principais entraves ao armazenamento e recuperação da informação. O ciberespaço é virtualmente infinito. Mas a virtualidade, aliada à rápida mudança dos suportes de informação, o que hoje é novo depressa fica obsoleto, coloca problemas que até hoje não eram sentidos, sobretudo a salvaguarda da memória e o medo da perda irreparável de documentos, ou livros que não tenham a sua materialidade assegurada.

\section{As bibliotecas públicas na era da informação}

O suportes informáticos estão agora presentes praticamente em todas as organizações e dadas as suas características dão origem a uma quantidade de informação cada vez maior. Hoje as empresas e praticamente a maioria dos indivíduos, pelo menos nos países ditos desenvolvidos ou em vias de desenvolvimento, recorrem ao computador para criar, tratar, 
utilizar e conservar as informações necessárias às suas atividades. Tal como as empresas e outros organismos as bibliotecas passaram a utilizar os suportes informáticos com as vantagens e desvantagens inerentes. Entre as primeiras, estão as que referimos em geral para a sociedade em rede, particularmente a libertação dos tradicionais obstáculos á informação e documentação, bem como as novas possibilidades a nível de acesso e difusão da coleção biblioteconómica e o trabalho em rede com o público leitor e com outras bibliotecas.

A nível das desvantagens estão naturalmente a fragilidade que anda associada aos novos suportes e a virtualidade da documentação ou livros que circulam no ciberespaço. É que tal fragilidade, aliada com a rapidez de evolução com que as tecnologias do hardware e software têm evoluído, levanta um sério problema à salvaguarda dos textos eletrónicos. Uma das grandes mudanças que anda associada a estes novos suportes e novas tecnologias da informação é o aparecimento do texto eletrónico, ou livro digital, que, tal como diz Roger Chartier, se apresenta com três características que transformam profundamente a nossa relação com a cultura escrita. A primeira é que a representação eletrónica da escrita modifica radicalmente a noção de contexto e o processo mesmo da construção do sentido, em grande parte porque "substitui a contiguidade física dos textos de um mesmo livro, pela distribuição móvel das arquiteturas das bases de dados" (Chartier, 1997, 23). A segunda, porque redefine a materialidade das obras, dando ao leitor, e não ao autor e editor, o domínio da composição do texto. A terceira, porque ao ler "sobre o écran o leitor contemporâneo reencontra algo da postura do leitor da antiguidade", lê um rolo que se desenrola agora verticalmente; um rolo que está dotado das características do livro desde o códex, nomeadamente, a paginação e os índices.

Mas o valor acrescentado que o texto eletrónico trouxe é também evidente e de grandes repercussões a nível da produção e difusão de livros. De facto, a versatilidade das novas tecnologias tende a apagar as distinções entre os processos separados de criação, reprodução, e distribuição de livros; em qualquer momento se pode controlar o processo. Por exemplo, o antigo circuito: autor, impressor/tipógrafo, livreiro, leitor; pode ser agora alterado: o próprio leitor pode ser criador e difundir o livro. Do mesmo modo, a imaterialidade das representações eletrónicas faz diminuir os custos produção e de reprodução dos livros. Enfim há ainda um conjunto de características non-book que revolucionaram os velhos circuitos do livro e que foram referenciadas por Afonso Furtado (2000, 361): enorme capacidade de armazenamento de dados, rapidez da sua produção e 
disseminação, facilidade de atualização e correções, potencialidades colaborativas e interativas.

As bibliotecas sempre acompanharam as mutações que as tecnologias provocaram no livro e na leitura. Consideramos que, ontem como hoje, a biblioteca sobretudo a biblioteca pública, tem uma dupla finalidade: garantir a memória e promover o conhecimento. Para isso, deve reunir uma coleção o mais vasta quanto possível de livros e outros meios de informação, para os disponibilizar aos leitores e assim ser uma autêntica "casa da sabedoria". Consequentemente a coleção deve ser preservada e aumentada continuamente.

O sonho de reunir num único espaço, ou numa única biblioteca, todos os livros publicados, para assim ter reunido todo o conhecimento baseado nos textos escritos, remonta pelo menos ao tempo da Biblioteca de Alexandria. As descrições que nos chegam documentam esse sonho da magnífica biblioteca:

Este espaço foi aumentando até a biblioteca albergar cerca de meio milhão de rolos, para além de mais quarenta mil guardados num outro edifício (...). Os volumes tinham de ser colecionados em elevado número, visto que o objetivo magnífico da biblioteca consistia em englobar a totalidade do conhecimento humano. Para Aristóteles, colecionar livros fazia parte do labor do erudito, necessário «como uma espécie de memorando». A biblioteca da cidade fundada pelo seu discípulo seria simplesmente uma versão mais vasta deste conceito: a memória do mundo (Manguel, 2010,96).

Hoje o sonho da universal disponibilidade dos textos e livros, o sonho de uma biblioteca universal, parece ser possível, mas não deve deslumbrar. Não só, porque a conversão eletrónica de todos os textos não pode significar o esquecimento, ou pior a destruição, dos impressos e manuscritos, mas também porque a biblioteca de hoje tem de salvaguardar o património bibliográfico, para garantir a memória e para isso tal como no passado, é necessário: recolher, fixar e preservar.

Ontem como hoje a biblioteca enfrenta outro perigo: o excesso, a multiplicação e proliferação de textos. $\mathrm{O}$ excesso pode gerar a angústia do bibliotecário, mas um dos problemas que terá de enfrentar é a desmotivação do leitor. Costuma-se dizer que luz demais cega, também o facto de termos agora acesso a tantos livros pode ser fator de desmotivação da leitura. Neste domínio não resistimos a recorrer ao testemunho de Eça de Queirós. Na obra Cidade e As Serras, o personagem central, a que Eça chama de forma familiar "o meu amigo Jacinto" e outras vezes "o meu Príncipe", vivia em Paris e 
tinha no seu palácio nos Campos Elísios, uma biblioteca que Eça descreve de forma magistral:

... eu escapei, respirando, para a biblioteca. Que majestoso armazém dos produtos do Raciocínio e da Imaginação! Ali jaziam mais de trinta mil volumes, e todos decerto essenciais a uma cultura humana. Logo à entrada notei, em ouro numa lombada verde, o nome de Adam Smith. Era pois a região dos Economistas. Avancei - e percorri, espantado, oito metros de Economia Política. Depois avistei os Filósofos e os seus comentadores, que revestiam toda uma parede, desde as escolas Pré-socráticas até às escolas Neopessimistas. Naquelas pranchas se acastelavam mais de dois mil sistemas - e que todos se contradiziam (Queirós, 1987, 51).

Jacinto, que além da biblioteca tinha em casa todas as tecnologias do momento, vivia enfastiado e desiludido e amaldiçoava, não só os livros mas sobretudo a civilização e todas as tecnologias. Ao fascínio inicial, pelos novos inventos e pelos livros, seguiu-se o tédio e desinteresse. No meio do seu fastio, quando pretendeu encontrar um livro para ler, não foi capaz de se decidir por nenhum:

Apanhava, folheava, arremessava; para desentulhar um volume, demolia uma torre de doutrinas.(...) na ânsia de encontrar um Livro! Parou então no meio da imensa nave, de cócoras, sem coragem, contemplando aqueles muros todos forrados, aquele chão todo alastrado, os seus setenta mil volumes - e, sem lhes provar a substancia, já absolutamente saciado, abarrotado, nauseado pela opressão da abundância (Queirós, 1987, 126).

Mas depois de regressar à sua aldeia de Tormes Jacinto ganhou outra vida, outra vontade pela leitura e redescobriu a delícia de ler um livro:

Essa mesma Natureza, que o desligara das ligaduras amortalhadas do tédio, e lhe gritava o seu belo Ambula, caminha! - também certamente lhe gritava et lege, e lê. E libertado enfim do invólucro sufocante da sua Biblioteca imensa, o meu ditoso amigo compreendia enfim a incomparável delícia de «ler um livro». Quando eu correra a Tormes (depois das revelações do Severo na venda do Torto), ele findava o D. Quixote, e ainda eu lhe escutara as derradeiras risadas com as coisas deliciosas, e decerto profundas, que o gordo Sancho the murmurava, escarranchado no seu burro. Mas agora o meu Príncipe mergulhara na Odisseia - todo ele vivia no espanto e no deslumbramento de assim ter encontrado no meio do caminho da sua vida, o velho errante, o velho Homero! (Queirós, 1987, 184).

O exemplo queirosiano aponta para a necessidade de libertação do excesso, de acumular livros como se tal acumulação fosse sinónimo de adquirir conhecimento, lembrando as 
ideias de Decimo Ausónio Magno a este propósito². Aponta também para um reencontro com o prazer ou conforto que a leitura proporciona. Ideias que pensamos ter atualidade na era de informação em que vivemos e onde nas nossas bibliotecas se acumulam cada vez mais livros que como já definiu Sahayle Ranganathan, nas cinco leis da biblioteconomia, só faz sentido se forem usados e tiverem leitores.

De facto, é perante esta dupla ansiedade, entre o excesso e o medo da perda, que a biblioteca de hoje e de amanhã tem um papel decisivo que passa, em primeiro lugar, por promover a leitura, redescobrir o prazer ou delícia de ler um livro. Nesse sentido, e retomando as ideias de Roger Chartier, compete às bibliotecas e particularmente aos bibliotecários, "reconstruir as sociabilidades perdidas" em torno do livro e da leitura. Alguns bons exemplos podem ser, o de retomar as práticas de leitura em voz alta, declamação de poesia, exposições sobre autores e outras do género.

Cabe também à biblioteca valorizar o seu património bibliográfico e dá-lo a conhecer. Neste domínio a biblioteca pública deve proceder á migração dos textos mais valiosos da sua coleção do seu tradicional suporte: o impresso ou manuscrito, para o digital. O bibliotecário deve estar alertado para o facto que as épocas das grandes revoluções da informação têm sido épocas de grandes destruições dos antigos suportes. Salvar o texto pode ser sinónimo de o resgatar do antigo suporte. Um bom exemplo é a necessidade imperiosa de passar para digital os textos de jornais e revistas, que por causa da qualidade do papel sobretudo depois da invenção da celulose, vão ficando ilegíveis.

Um outro papel para a biblioteca da nossa era é o de ser a instituição que está na linha da frente contra a infoexclusão e, por isso, as suas portas devem estar abertas a todos os que por razões sociais e económicas não tenham possibilidade de acesso ao livro e leitura nos múltiplos suportes. A biblioteca deve promover as várias literacias que agora se fala, nomeadamente, da informação e financeira.

Vemos a biblioteca pública da nossa época com um papel decisivo na criação do "espaço público", onde qualquer cidadão pode encontrar os meios para aceder ao conhecimento e para o partilhar com os outros cidadãos. E porque o conhecimento é das poucas coisas que se multiplica quando se partilha, a biblioteca assemelha-se como nos diz Umberto Eco a uma "mente divina", embora gostemos mais da metáfora que Frei Manuel do Cenáculo usava, a biblioteca como a "Casa da Sabedoria".

\footnotetext{
${ }^{2}$ Manguel $(2010,107)$ cita a seguinte passagem: «Compraste livros e encheste estantes, Ó amante das Musas. Quer isso dizer que és agora erudito? Se comprares instrumentos de corda, plectro e lira hoje: julgas que amanhã o reino da música será teu?».
} 


\section{Referências bibliográficas}

CASTELLS, Manuel (2007) - A Era da Informação, Economia, Sociedade e Cultura- A Sociedade em Rede. Lisboa: Gulbenkian.

CASTELLS, Manuel (2005) - A Sociedade em Rede: do Conhecimento à Politica. A Sociedade em Rede do Conhecimento à Ação Politica, org. CASTELLS, Manuel e CARDOSO, Gustavo, Lisboa: Imprensa Nacional Casa da Moeda, p. 17-30. Disponível em: http://www.cies.iscte.pt/destaques/documents/Sociedade_em_Rede_CC.pdf_ (Consultado em: 3-3-2015).

CHARTIER, Roger (2001) - Lecteurs et lectures à l' age de la textualité électronique, disponivel em : http://cv.uoc.edu/ 04_999_01_u07/chartier2.html [ Consultado em 13-1014].

CHARTIER, Roger (1997) - A Ordem dos Livros. Lisboa: Vega.

DARNTON, Robert, (2000) - An Early information Society. News and media in eighteenth - century Paris. The American Historical Review, $\mathrm{n}^{\circ}$ 105, p. 32. Disponível em: http://www.historians.org/info/aha_history/rdarnton.html. [Consultado em 5-09-2013]. FURTADO, José Afonso (2000) - Os Livros e as Leituras. Novas Ecologias da Informação. Mem Martins: Livros e Leituras.

LEVINSON, Paul (1998) - A Arma Suave. História Natural da Revolução da Informação. Lisboa: Bizâncio.

MANGUEL, Alberto (2010) - Uma História da Leitura. Lisboa: Editorial Presença. QUEIRÓS, Eça - A Cidade e as Serras. Lisboa: Europa América, 1987. (1 $1^{\text {a }}$ ed. 1901). ROUSSEAU, Jean e COUTURE, Caro (1998) - Os Fundamentos da Disciplina Arquivística. Lisboa: Publicações D. Quixote. 